\title{
IN-DEPTH SURVEY REPORT: \\ CONTROL OF AIRBORNE SOLVENTS IN A \\ SMALL OFFSET PRINT SHOP
}

\author{
at \\ Economy Printing \\ Parchment, Michigan
}

\author{
REPORT WRITTEN BY \\ Kelth $\mathrm{G}$ Crouch \\ Michael G Gressel
}

REPORT DATE

September 1996

REPORT NO

ECTB 205-12a
U S DEPARTMENT OF HEALTH AND HUMAN SERVICES
Public Health Service
Centers for Disease Control and Prevention
National Institute for Occupational Safety and Health.
Division of Physical Sciences and Engineering
4676 Columbıa Parkway, R5
Cincinnat, Ohio 45226


PLANT SURVEYED

SIC CODE

SURVEY DATE

SURVEY CONDUCTED BY

EMPLOYER REPRESENTATIVE CONTACTED

EMPLOYEE REPRESENT ATIVE CONTACTED

ANALYTICAL WORK PERFORMED BY

MANUSCRIPT PREPARED BY
Economy Pronting

600 Shopper's Lane

Parchment, Michigan 49004

2752

May 8-10 \& 22-24, 1995

Ketth $\mathrm{G}$ Crouch

Denris $M O^{\prime} B$ rien

Daniel R Farwick

Donald J Murdock, Jr

Bruce Hannapel

President

Economy Prontung

No Union

Data Chem

Bernice L Clark

Robin Smith 


\section{DISCLAIMER}

Mention of company names or products does not constitute endorsement by the Centers for Disease Control and Prevention (CDC) 


\section{INTRODUCTION}

This report contains the results of personal exposure and area sampling for airborne solvent vapors conducted at a small printıng establishment during two visits in May 1995 Also included are the sampling methods, the exposure standards, ventilation flow measurements, and some recommendations for follow-up work Between the visits, a heat recovery ventulator (HRV) containing an air-to-air heat exchanger (United Aur Specialısts, Inc, Cincınnatı, OH) was unstalled to remove stale air and supply fresh dilution an to the two press rooms The sampling data prouded a basis for evaluating the effectrveness of the HRV in reducing personal exposure levels to the arborne solvent vapors

\section{SOLVENT EXPOSURES: AIRBORNE AND SKIN CONTACT}

Time-weighted average concentrations of arrborne solvent vapors that the press operators were exposed to are shown in Tables 1-6 Tables 3 and 5 cover the same operator Employees are exposed to several solvent vapors simultaneously, and these vapors have some adverse health effects in common Therefore, additive levels are shown in bar charts, as well as levels for the individual species Because their concentrations were negligible compared to the other solvents, the contribution to the additive concentrations of $1,1,1$ trichloroethane, toluene, ethyl benzene, and cumene were not shown Definition of the exposure standards is given in Attachment 1 , and detals of the calculation of the additive exposure levels can be found in Attachment 2

The horizontal bar charts of cumulative exposures and Table 8 show that before the fresh arr supply was added, six of erght personal exposure samples for the press operators were at or above 50 percent of the Permissible Exposure Limit (PEL) After the addition of a fresh atr supply, no exposures were above 50 percent of the PEL These results are based upon the narcotic effects of the solvents, which is the basis for the PELs for all the solvents except methylene chloride and

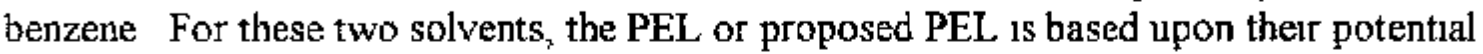
carcinogenic effects For purposes of estimating additıve exposures only, the PELs for narcotic effects for methylene chloride and benzene were approximated as $200 \mathrm{ppm}$, based upon statements found in the toxicological literature [Federal Register, 29 CFR Parts 1910, 1915 and 1926, Occupational Exposure to Methylene Chloride, Proposed Rule, 66 (216) 57080-57081, 1991, and Documentation of the Threshold Limit Values and Biological Exposure Indices, Benzene, ACGIH, 1991, p 113] These two compounds are not, in this case, large contributors to the cumulative PEL, so even moderate errors in estımating their narcotic PELs would have little or na effect on our conclusions

However, based upon the carcinogenc potential of methylene chlonde, after installation of the fresh ar system, two samples for the press operators were still over the Recommended Exposure Lums (REL) of $25 \mathrm{ppm}$, and one was between the REL and 50 percent of the REL See Attachment 2 for further detals The NIOSH action level for methylene chloride is $125 \mathrm{ppm}$

Tables 7 and 8 show cumulatve concentrations before and after control installation The average cumulative concentration as determuned by the area sampling was reduced by $58 \pm 11 \%(95 \%$ 


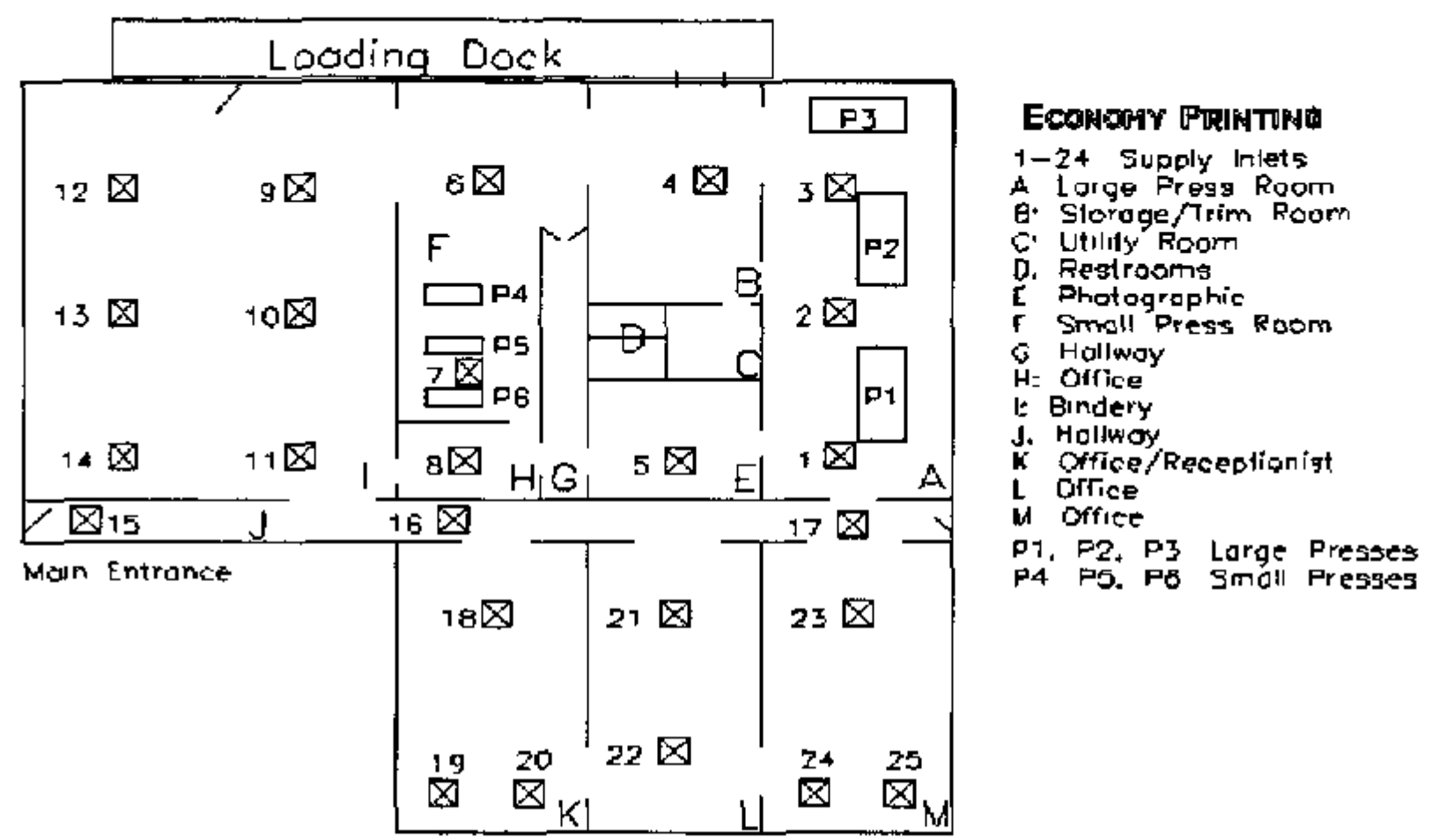

confidence interval) as a result of control installation The average cumulative concentration determined from the personal sampling was reduced by $54 \pm 13 \%$ These concentratıons were not normalized for solvent usage rates, and day-to-day variations are obviously large, so the contribution of the control to concentration seduction has significant uncertainty

Skin contact with solvents can cause dermatitıs, and some can be absorbed through the skin Press operators should wear impermeable gloves when performing cleanng operations Solvent manufacturers can suggest appropriate glove materials (on the Material Safety Data Sheets) Methylene chlonde, toluene, xylene, ethyl benzene, and cumene, for example, can all be absorbed through the skin to a significant extent, in addition to the arrborne route of exposure Therefore, press operators may have higher solvent exposures than indicated by the results of our arborne sampling In order to evaluate the total absorbed from these multiple exposure routes, biological sampling of the employee's blood, urme, or expired air is necessary The primary concern in this study was the arborne exposure route, since the skin absorption route can be controlled through the use of gloves, so bological sampling was not conducted If glove wearing cannot be assured, it would be necessary to carry out buological sampling of the press operators to see if the additional absorption through skın contact resulted in a health hazard

\section{VENTILATION SYSTEMS}

The facility had two HVAC systems that mixed and recrrculated the arr throughout the buldung They had no provision for the introduction of outside atr Three supply inlets $(1,2$, and 3$)$ fed by an HVAC system provided $512 \mathrm{cfm}$ total to the large press room Two inlets (7 and 8) supplied $222 \mathrm{cfm}$ total to the small press room The two retum inlets for these bunlding HVAC systems 
were located in the hallway (J) and in an office, room L

The new fresh arr system, which includes the arr-to-air heat exchanger, supplied a total of $742 \mathrm{cfm}$ of fresh arr, $427 \mathrm{cfm}$ to the large press room, and $315 \mathrm{cfm}$ to the small press room It removed a total of about $716 \mathrm{~cm}$ from the press areas, $406 \mathrm{~cm}$ from the large press room, and $310 \mathrm{~cm}$ from the small press joom In each of the press rooms, the fresh arr was admutted from celling outlets at one end of the room and removed from celling inlets at the other end of the room In a smoke release study, some of the smoke released in the press rooms tended to drift slowly into adjacent areas of the bulding

\section{RECOMMENDATIONS}

Although the addition of the fresh alr system did reduce solvent vapor concentrations, significant further improvement can be made at little additional cost

The solvent concentration data shows a relatively uniform distributton of solvent vapors throughout the bulding The alm of the following modifications is to contatn the solvent emissions to the press rooms and prevent their spread throughout the building This will facilitate the control of the arrborne solvents and reduce the exposure of non-press personnel To begin, the two press rooms should be maintaned at a negatjve pressure with respect to other areas of the bulling Thus can be accomplished, in part, by closing off the large openings between the press rooms and other areas with a combination of walls and/or doors Second, the fresh air system ducting should be partally redone Please refer to the Diagram on the following page It should stlll exhaust all of its air from the two press rooms, but the fresh makeup air should be routed into the return side of the two butding HVAC systems, rather than directly into the two press rooms, as it does currently The rate of flow through the supply inlets for the HVAC systems in the two 


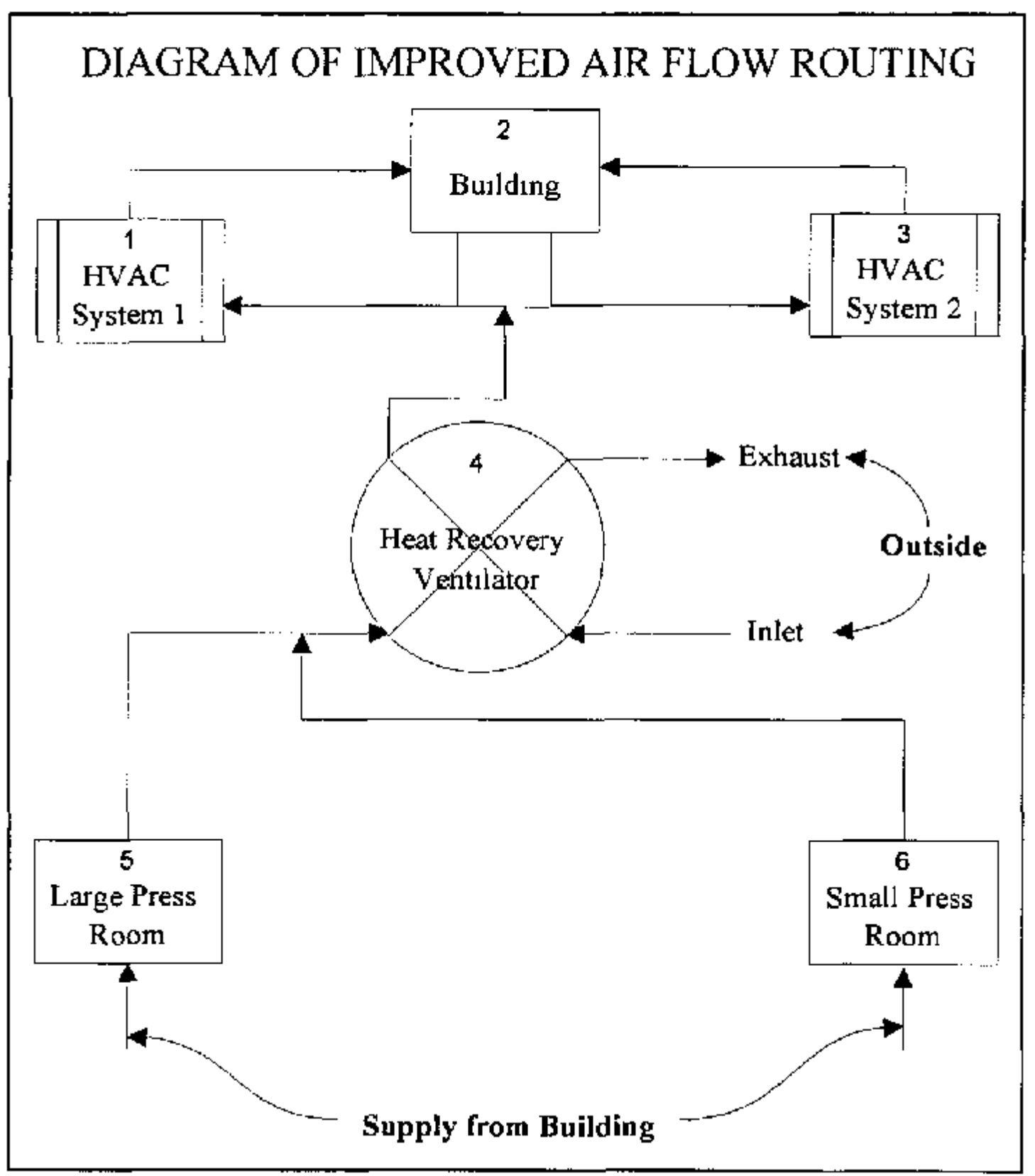

press rooms should be reduced to maintain a slight negative pressure These measures will ensure that the rnakeup air for the press rooms will flow into the rooms from adjacent areas of the bulding, reducing the spread of arbome material out of the press rooms Finally, by placing the exhaust inlets for the fresh air system as close as possible to the solvent emission sites on the presses, the solvent concentrations in the press rooms can also be minumzed On the small presses, a single exhaust pont near the paper delivery point (see the photo) has been effective On the large, two-color presses, an additional exhaust point near the roller train for the second color would be necessary for good control 
If effective substitutes can be found, replace solvents that contam methylene chloride with ones that are free of it Be sure that the replacement solvents contain no potentially carcinogenic or otherwise highly toxic components (avold benzene, for example)

The following suggestons affect the maintenance and efficiency of the ventilation control systems discussed above The ducts should be smooth on the inside and have a circular cross-section This minimizes dust accumulation in the duct and ressstance to arr flow Also, round duct withstands larger negative pressures, and can be cleaned, in contrast to most flexuble, corrugated, or rectangular duct The duct should be sized to mantan at least 3000 feet per minute atr velocity in the duct to prevent settling and accumulation of the ant1-offset powder inside honzontal duct runs There should be a dust filter at the inlet to the fresh atr system to protect the ast-to-alr heat exchanger from degradation caused by dust accumulation The use of an electrostatic precipitator at this point might also be effective The anti-offset powder can otherwise bu1d up quickly, resulting in a recurrent manntenance problem

If these recomrnended changes are made, employee exposures to solvents should be reduced below levels currently considered or anticipated to be hazardous The nusance caused by ant1offset dust from the printing operatıons settling throughout the buldung can be largely avolded 


\section{TABLE 1}

LARGE PRESS OPERATOR A

\begin{tabular}{lccccccc}
\hline \multicolumn{1}{c}{ Solvent } & $5 / 9 / 95$ & $5 / 10 / 95$ & $5 / 23 / 95$ & $5 / 24 / 95$ & TLV & REL & PEL \\
\hline Methylene Chlonde & 196 & 362 & 319 & 104 & 50 & 25 & 500 \\
1,1,1 Trichloroethane & 34 & 64 & 00 & 00 & 350 & 350 & 350 \\
Toluene & 02 & 02 & 01 & 01 & 50 & 100 & 100 \\
Xylene & 27 & 49 & 29 & 12 & 100 & 100 & 100 \\
Ethyl Benzene & 08 & 16 & 09 & 04 & 100 & 100 & 100 \\
Cumene & 01 & 01 & 01 & 00 & 50 & 50 & 50 \\
Trinethyl Benzene & 23 & 26 & 16 & 09 & 25 & 25 & 25 \\
Other Hydrocarbons* & 158 & 231 & 138 & 68 & $* 100$ & $* 60$ & $* 500$ \\
Samping Tinge, frin & 481 & 432 & 435 & 516 & & \\
*-Treated as Stoddard Solvent & & & & & & & \\
\hline
\end{tabular}

TABLE 2

LARGE PRESS OPERATOR B

\begin{tabular}{|c|c|c|c|c|c|c|c|}
\hline \multicolumn{8}{|c|}{ CONCENTRATION, ppm } \\
\hline Solvent & $5 / 9 / 95$ & $5 / 10 / 95$ & $5 / 23 / 95$ & $5 / 24 / 95$ & TLV & REL & PEL \\
\hline Methylene Chloride & 90 & 264 & 319 & 104 & 50 & 25 & 500 \\
\hline 1,1,1 Trıchloroethane & 21 & 01 & 00 & 00 & 350 & 350 & 350 \\
\hline Toluene & 02 & 02 & 02 & 01 & 50 & 100 & 100 \\
\hline Xylene & 19 & 37 & 15 & 09 & 100 & 100 & 100 \\
\hline Ethyl Benzene & 06 & 12 & 04 & 02 & 100 & 100 & 100 \\
\hline Cumene & 01 & 01 & 01 & 01 & 50 & 50 & so \\
\hline Trnmethyl Benzene & 23 & 33 & 16 & 18 & 25 & 25 & 25 \\
\hline Other Hydrocarbons* & 127 & 213 & 108 & 76 & $* 100$ & $* 60$ & $* 500$ \\
\hline Sampling Time, min & 442 & 507 & 444 & 226 & & & \\
\hline * - Treated as Stoddar & & & & & & & \\
\hline
\end{tabular}


TABLE 3

LARGE PRESS OPERATOR C

\begin{tabular}{|c|c|c|c|c|c|}
\hline \multicolumn{6}{|c|}{ CONCENTRATION, ppm } \\
\hline Solvent & $5 / 23 / 95$ & $5 / 24 / 95$ & TLV & REL & PEL \\
\hline Methylene Chlonde & 173 & 91 & 50 & 25 & 500 \\
\hline 1,1,1 Trichlorocthane & 00 & 00 & 350 & 350 & 350 \\
\hline Toluene & 01 & 01 & 50 & 100 & 100 \\
\hline Xylene & 18 & 10 & 100 & 100 & 100 \\
\hline Ethyl Benzene & 05 & 29 & 100 & 100 & 100 \\
\hline Cumene & 01 & 00 & 50 & 50 & 50 \\
\hline Trımethyl Benzene & 13 & 07 & 25 & 25 & 25 \\
\hline Other Hydrocarbons* & 110 & 53 & ${ }^{*} 100$ & $* 60$ & $* 500$ \\
\hline $\begin{array}{l}\text { Sampling Tume, min } \\
\text { * - Treated as Stoddar }\end{array}$ & 507 & 531 & & & \\
\hline
\end{tabular}

TABLE 4

SMALL PRESS OPERATUR A

CONCENTRATION, ppm

\begin{tabular}{|c|c|c|c|c|c|c|c|}
\hline Solvent & $5 / 9 / 95$ & $5 / 10 / 95$ & $5 / 23 / 95$ & $5 / 24 / 95$ & TLV & REL & PEL \\
\hline Methylene Chlonde & 433 & 539 & 342 & 42 & 50 & 25 & 500 \\
\hline 1,1,1 Trichloroethane & 05 & 06 & 00 & 00 & 350 & 350 & 350 \\
\hline Toluene & 01 & 02 & 01 & 00 & 50 & 100 & 100 \\
\hline Xylene & 47 & 64 & 33 & 07 & 100 & 100 & 100 \\
\hline Ethyl Benzene & 16 & 20 & 10 & 02 & 100 & 100 & 100 \\
\hline Cumene & 00 & 01 & 00 & 00 & 50 & 50 & 50 \\
\hline Trımethyl Benzene & 13 & 16 & 06 & 03 & 25 & 25 & 25 \\
\hline Other Hydrocarbons* & 187 & 254 & 138 & 29 & $* 100$ & $* 60$ & $* 500$ \\
\hline Sampling Time, nth & 491 & 488 & 464 & 134 & & & \\
\hline \multicolumn{8}{|c|}{ * - Treated as Stoddard Solvent } \\
\hline
\end{tabular}




\begin{tabular}{lcccc}
\hline \multicolumn{5}{c}{ TABLE 5 } \\
\multicolumn{5}{c}{ SMALL PRESS OPERATOR B } \\
\hline \multicolumn{1}{c}{ Colvent } & $5 / 9 / 95$ & TLV & REL & PEL \\
\hline Methylene Chlonde & 420 & 50 & 25 & 500 \\
$1,1,1$ Trichlojoethane & 04 & 350 & 350 & 350 \\
Toluene & 02 & 50 & 100 & 100 \\
Xylene & 55 & 100 & 100 & 100 \\
Ethyl Benzene & 18 & 100 & 100 & 100 \\
Cumene & 01 & 50 & 50 & 50 \\
Trimethyl Benzene & 20 & 25 & 25 & 25 \\
Total Hydrocarbons & 82 & $* 100$ & $* 60$ & $* 500$ \\
Sarmpling Tume, min, & 332 & & & \\
* - Treated as Stoddard Solvent & & & & \\
\hline
\end{tabular}

TABLE 6

SMALL PRESS OPERATOR C CONCENTRATION, ppm

\begin{tabular}{lcccccc}
\multicolumn{1}{c}{ Solvent } & $5 / 10 / 95$ & $5 / 23 / 95$ & $5 / 24 / 95$ & TLV & REL & PEL \\
\hline Methylene Chlonde & 362 & 225 & 132 & 50 & 25 & 500 \\
l,1,1 Trichloroethane & 74 & 00 & 00 & 350 & 350 & 350 \\
Toluene & 02 & 01 & 00 & 50 & 100 & 100 \\
Xylene & 70 & 38 & 22 & 100 & 100 & 100 \\
Ethyl Benzene & 22 & 11 & 07 & 100 & 100 & 100 \\
Cumene & 01 & 00 & 00 & 50 & 50 & 50 \\
Trimethyl Benzene & 19 & 05 & 04 & 25 & 25 & 25 \\
Total Hydrocarbons* & 253 & 141 & 89 & $* 100$ & $* 60$ & $* 500$ \\
Sampling Tume, mun & 474 & 453 & 495 & \\
*- Treated as Stoddard Solvent & & & & & & \\
\hline
\end{tabular}


Table 7. Summary of area sampling data.

\begin{tabular}{|c|c|c|c|c|c|c|c|c|}
\hline & \multicolumn{4}{|c|}{ Before } & \multicolumn{4}{c|}{ After } \\
\hline Date & \multicolumn{2}{|c|}{9} & \multicolumn{2}{c|}{10} & \multicolumn{2}{c|}{23} & \multicolumn{2}{c|}{24} \\
\hline Area & Cumulative & MeCl & Cumulative & MeCl & Cumulative & MeCl & Cumulative & MeCl \\
\hline Large Press & 024 & 044 & 042 & 081 & 016 & 038 & 008 & 0.11 \\
Small Press & 037 & 0.97 & 043 & 0.97 & 017 & 046 & 009 & 017 \\
Reception & 018 & 039 & 031 & 071 & 026 & 0.74 & 006 & 0.11 \\
Bindery & 02 & 0.52 & 032 & 068 & 012 & 038 & 008 & 019 \\
Photo & 022 & 0.42 & 039 & 11 & 014 & 037 & 006 & 012 \\
Supply & 019 & 037 & 035 & 11 & 012 & 034 & 006 & 01 \\
Trim & $*$ & $*$ & $*$ & $*$ & 021 & 056 & 01 & 015 \\
\hline Average & 0.23 & 0.52 & 0.37 & 0.90 & 0.17 & 0.46 & 0.08 & 0.14 \\
\hline
\end{tabular}

Cumblative Average Before 030

Cumulative Average After 012

$\mathrm{MeCl}$ Average Before 071

$\mathrm{MeCl}$ Average After $\quad 030$

* = Data not collected

Cumulative $=$ Cumulative concentration relative to the PEL, using $200 \mathrm{ppm}$ for the PEL of methylene chloride

$\mathrm{MeCl}=$ Concentration of methylene chiorice relative to its carcınogen $\mid \mathrm{C}$ PEL of $25 \mathrm{ppm}$

$\%$ Reduction in Cumulative concentration, $58+/-11$ (95\% confidence interval)

$\%$ Reduction in methylene chloride concentration, $52+/-16$ (95\% confidence interval) 
Table 8. Summary of personal sampling data.

\begin{tabular}{|c|c|c|c|c|c|c|c|c|}
\hline & \multicolumn{4}{|c|}{ Before } & \multicolumn{4}{|c|}{ After } \\
\hline Date & \multicolumn{2}{|l|}{9} & \multicolumn{2}{|l|}{10} & \multicolumn{2}{|c|}{23} & \multicolumn{2}{|c|}{24} \\
\hline Area & Cumulative & Meci & Cumulative & $\mathrm{MeCl}$ & Cumulative & $\mathrm{MeCl}$ & Cumulative & $\mathrm{MeCl}$ \\
\hline Press Operator 1 & 038 & 079 & 058 & 447 & 038 & 129 & 017 & 0.42 \\
\hline Press Operator 2 & 026 & 037 & 050 & 1,07 & 025 & 0,54 & 008 & 007 \\
\hline Press Operator 3 & 052 & 176 & 067 & 219 & 036 & 1.39 & 007 & $0 \leqslant 7$ \\
\hline Press Operator 4 & 059 & 170 & • & * & 026 & 070 & 013 & 037 \\
\hline Press Operator 5 & 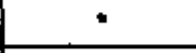 & 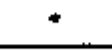 & 059 & 147 & 031 & 091 & 019 & 0.53 \\
\hline Averang & 0.44 & 1.16 & 0.59 & 1.55 & $\mathrm{D}_{2} 31$ & 0.97 & 013 & 231 \\
\hline
\end{tabular}

$\begin{array}{ll}\text { Cumulative Average Before } \quad 051 \\ \text { Cumulative Average After } & 022\end{array}$

MeCl Average Before 135

MeCi Average After 064

* = Worker absent

Cumulative $=$ Cumulative concentration relative to the $P E L$, using $200 \mathrm{ppm}$ for the PEL of methylene chloride $\mathrm{MeCl}=$ Concentration of methylene chloride relative to its carcinogenic PEL of $25 \mathrm{ppm}$

\% Reduction in Cumulative concentration, $54+1-13$ (95\% confidence interval)

$\%$ Reduction In methylene chloride concentration, $45+i-23$ (95\% confidence interval) 


\section{ATTACHMENT 1 \\ EXPOSURE STANDARDS}

The term time-werghted average (TWA) is apphted to an exposure which is averaged over the duration of the sampling, typically for a futl shift

TLVs - The American Conference of Governmental Industnal Hygienssts (ACGIH) recommends exposure hmits for chemcal and physical agents These limits are called Threshold Limit Values or TLVs and are widely recogruzed in the field of industral hygiene They are updated yearly as new information becomes avalable

(Amencan Conference of Governmental Industral Hygiensts 1993-1994 Threshold Lima Values for Chemical Substances and Physical Agents and Biological Exposure Indices Cincinnat ACGIH, 1993)

(American Conference of Governmental Industrial Hygienısts Annual Reports of the Commuttees on Threshold Limi Values and Brological Exposure Indices Cincinnats ACGIH, 1994)

PELs - The Occupational Safety and Health Administration (OSHA) is the federal regulatory agency which promulgates and enforces the legal limits for exposures to chemical and physical agents They are called PELs, or Permissible Exposure Limits Few changes have been made in the PELs since OSHA was onginated in 1971, and they are not generally considered to be the most protective lumis

(Air Contammants, Code of Federal Regulations Tute 29, Pan $19101000 \quad 1993$ )

RELs - The National Institute for Occupational Safety and Health (NIOSH) is a federal research organzation which recommends limits for chemical and physical agents They are called Recommended Exposure Litmits, or RELs, and are wedely recogruzed in the field of industral hygiene NIOSH's criterua for establishing standards are based on health effects and the most sensitive method avaltable for measuring contaminants, so RELs are often lower than other limits

(National Instutute for Occupational Safety and Health Pocket Gunde to Chemical Hazards, DHHS(NIOSH) Publication No 94-1 16 Cincinnat1 NIOSH, 1994) 


\section{ATTACHMENT 2 \\ PRINTING PROCESSES AND AIRBORNE SAMPLING METHODS}

Employees are involved in sales, layout, duplication, bindery, and press operatons The pnmary arborne contaminants are generated by press cleanup operatıons of the plate, rollers, and other press components of the seven offset lithographic presses Also, normal press operation unvolves some evaporation of ink solvents and fountain solutions Because of their proximity, the press operators could be expected to have the highest exposures to these arborne emissions

The sources of the arborne emissions of concern are likely the following products

Lithographuc Press Wash, Econo Wash - Low Odor (RBP Chemcal Corp)

Fast Dry Blanket and Roller Wash, \#10-00860 (Rogersol, Inc)

Full-shift personal sampling for solvents contaned in these products was conducted on five employees for all or part of four days Also, area sampling was conducted at six locations inside the bulding and one outside The results are shown in Tables 1-8 and in the charts titled Concentrations Relative to the PEL The personal sampling was discontinued during the employees' lunch break, and at other times when they left the bulding, and resumed when they returned The area sampling proceeded contnuously throughout the day

Both the personal and the area sampling made use of the sampling train shown in the dıagram The sampling inlets for the personal sampling were located in the breathing zone of the individuals, chpped to their collars The collection medium was coconut shell charcoal tubes (100 mg/50 mg) Aur for charcoal tubes $\mathrm{A}$ and $\mathrm{B}$ entered through inlet 2 at a rate of 10 $\mathrm{cm}^{3} / \mathrm{min}$ The charcoal tubes were analyzed using gas chromatography for the following species according to the NIOSH Manuat of Analytical Methods 1003 and 1005 with modifications 1,1,1-Tnchloroethane and Methylene Chlonde Air for charcoal tube $C$ entered through inlet 1 at a rate of $50 \mathrm{~cm}^{3} / \mathrm{mm}$ These charcoal tubes were analyzed by gas chromatography using Methods 1501 and 1550 with modifications for the following species Toluene, Xylene, Ethyl Benzene, Cumene, Trumethylbenzene and Total Hydrocarbons 
Additive exposures were calculated using the formula

$$
\mathrm{C}_{1} / \mathrm{L}_{1}+\mathrm{C}_{2} / \mathrm{L}_{2}+=\text { Additive Exposure, }
$$

where $\mathrm{C}$ is the measured exposure for a species and $\mathrm{L}$ is the corresponding exposure limit Additive exposures greater than 10 are considered overexposures

Tables 1-6 show the personal sampling results for the charcoal tube measurements The additive exposures for both personal and area sampling are shown in the bar charts, and in Tables 7 and 8 Note that the current exposure standards are given in the tables Also, the exposure standard used to calculate the contribution to additive exposures for methylene chlonde was estumated, based upon its narcotic effects A PEL of $200 \mathrm{ppm}$, and a TLV and REL of $100 \mathrm{ppm}$, established to avold its narcotic effects, were used for the additive exposures The additive exposures can, therefore, be considered as only an approxumate indicator of potential narcotic effects 


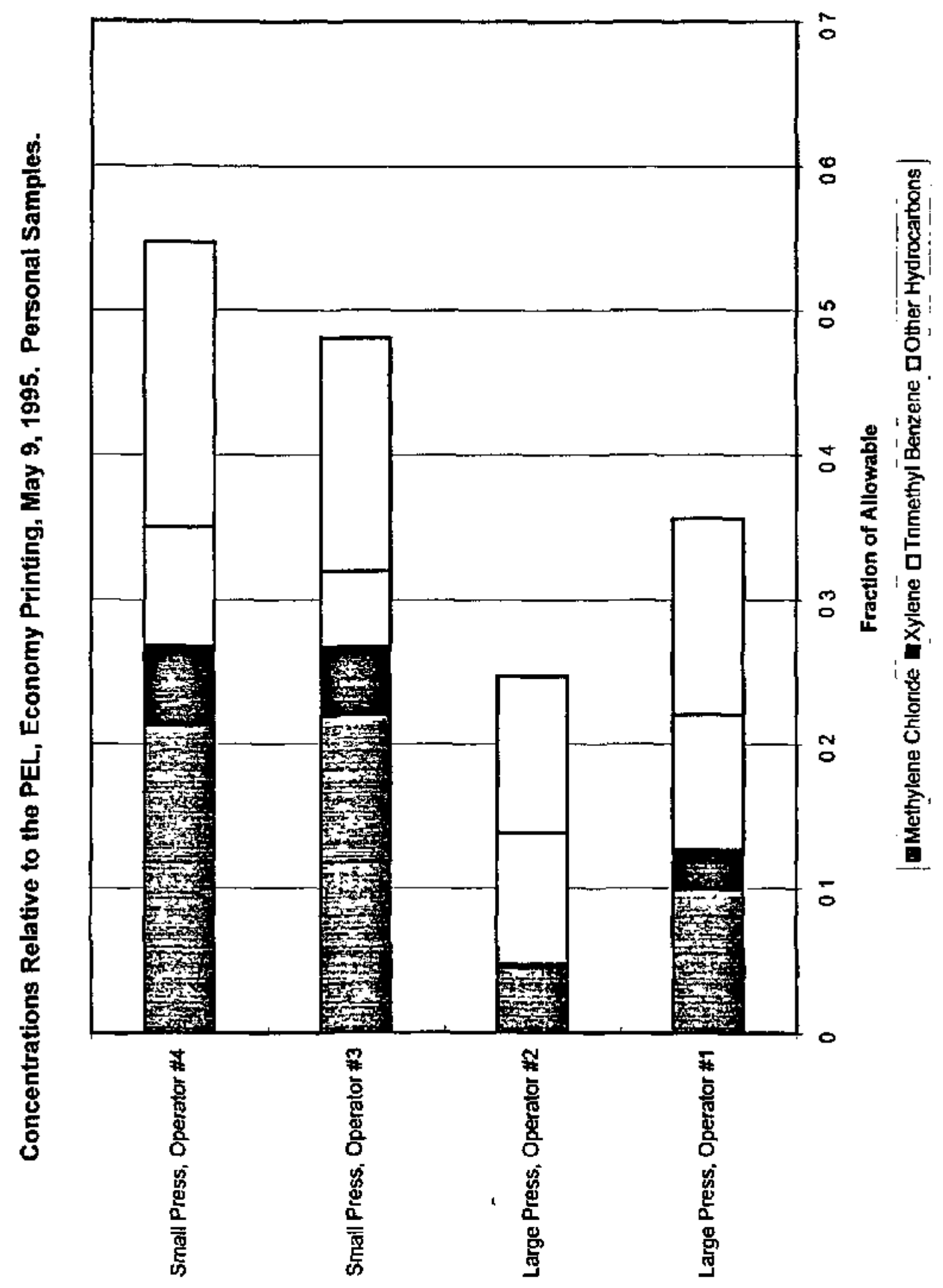




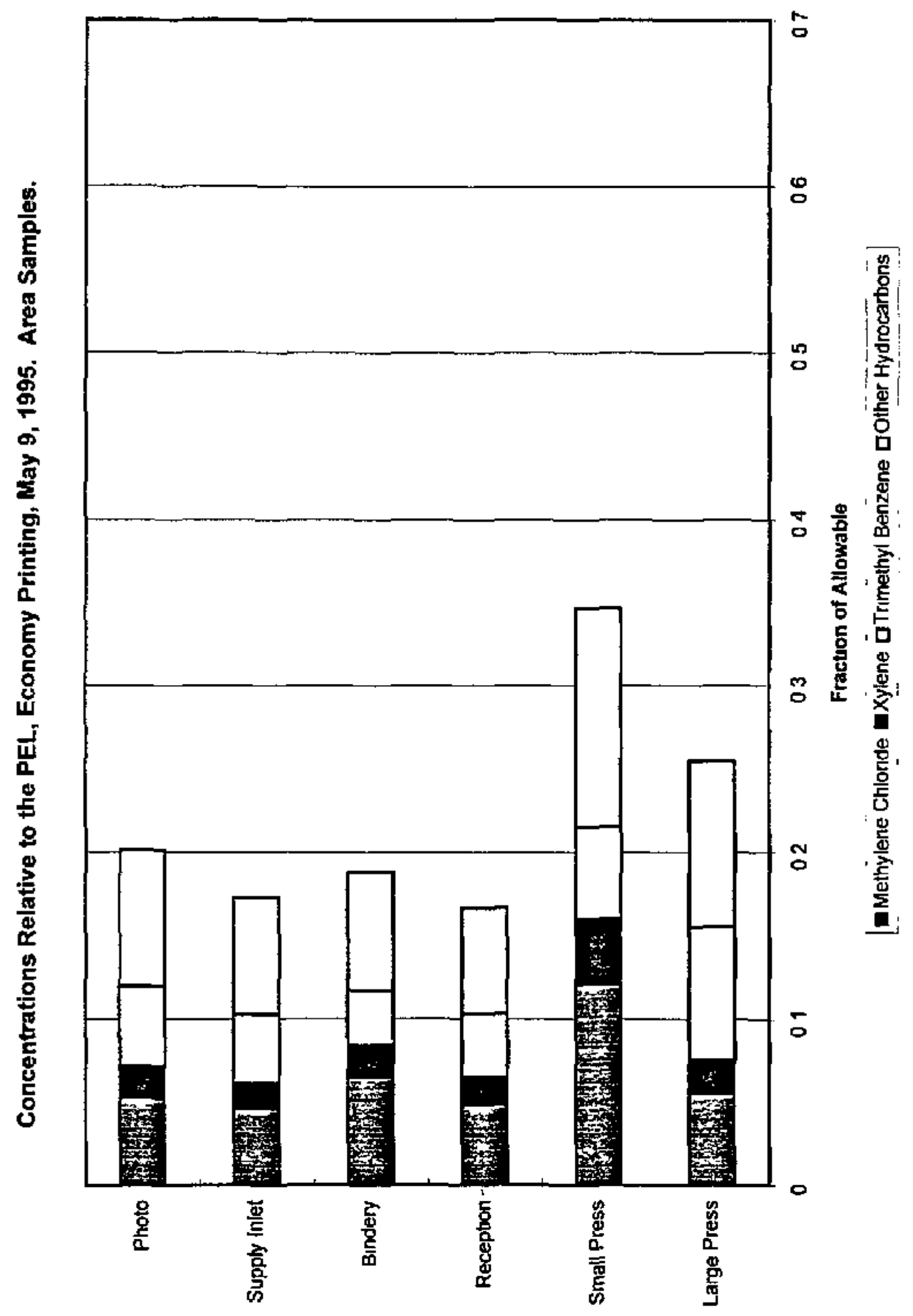




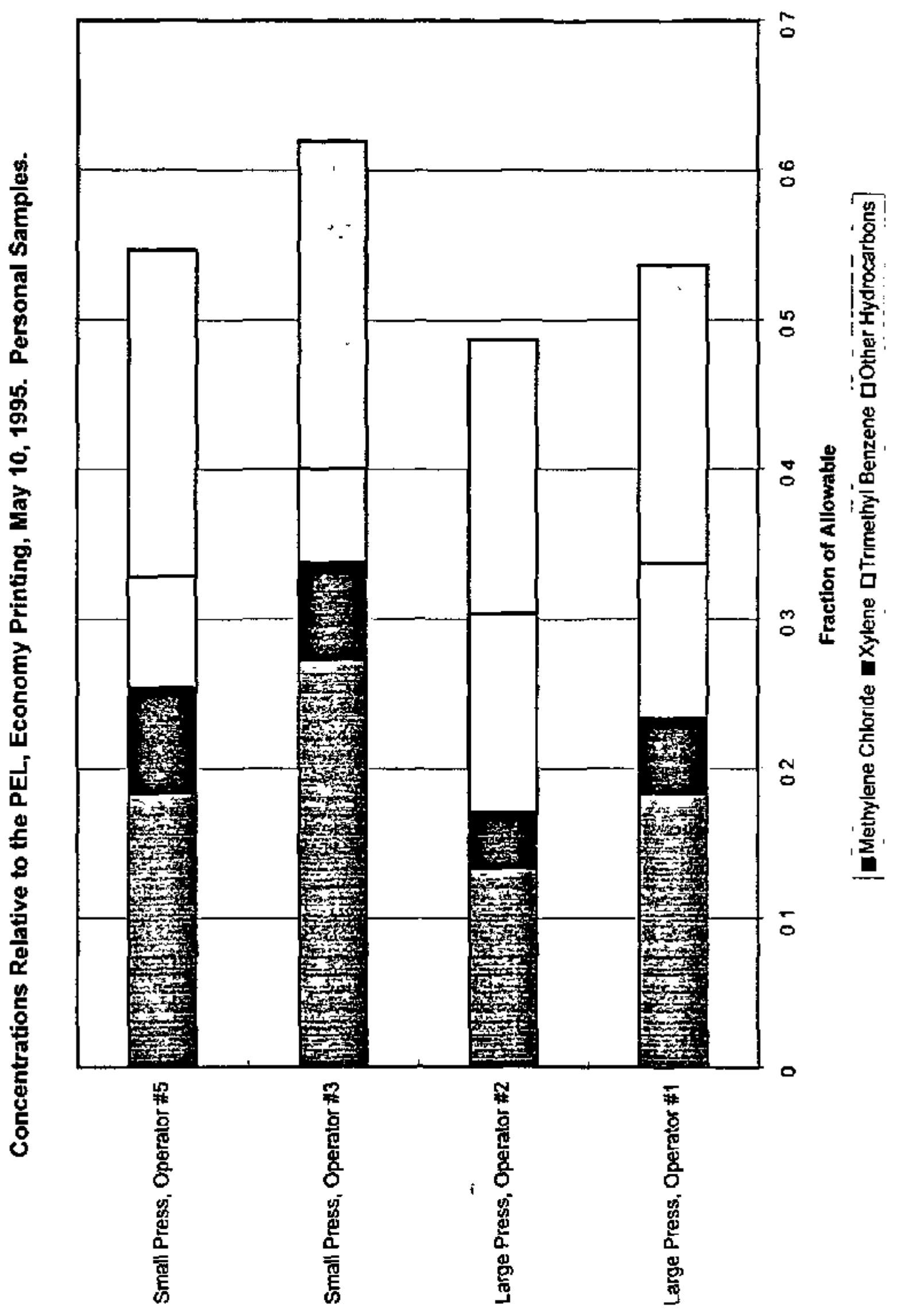




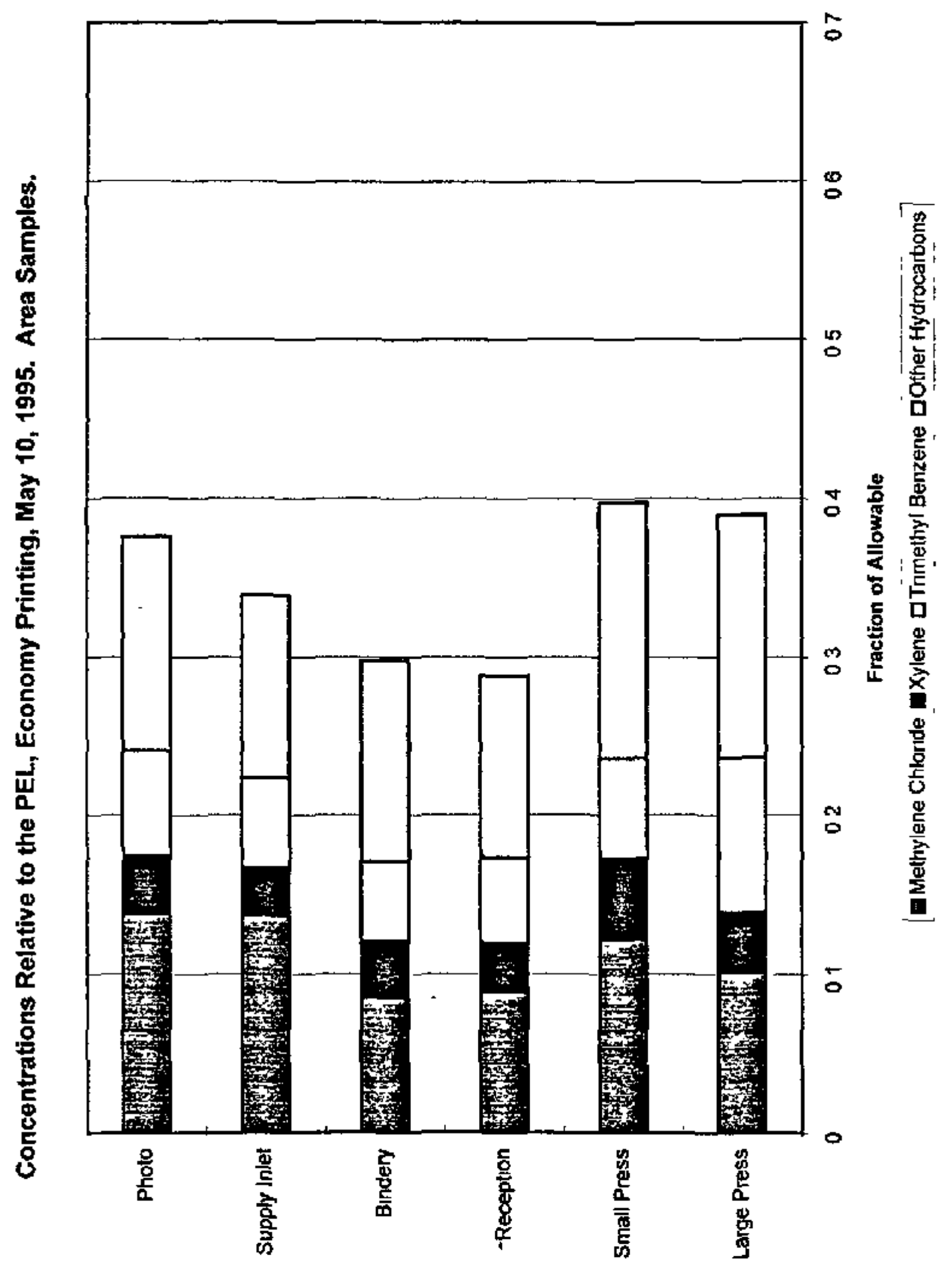




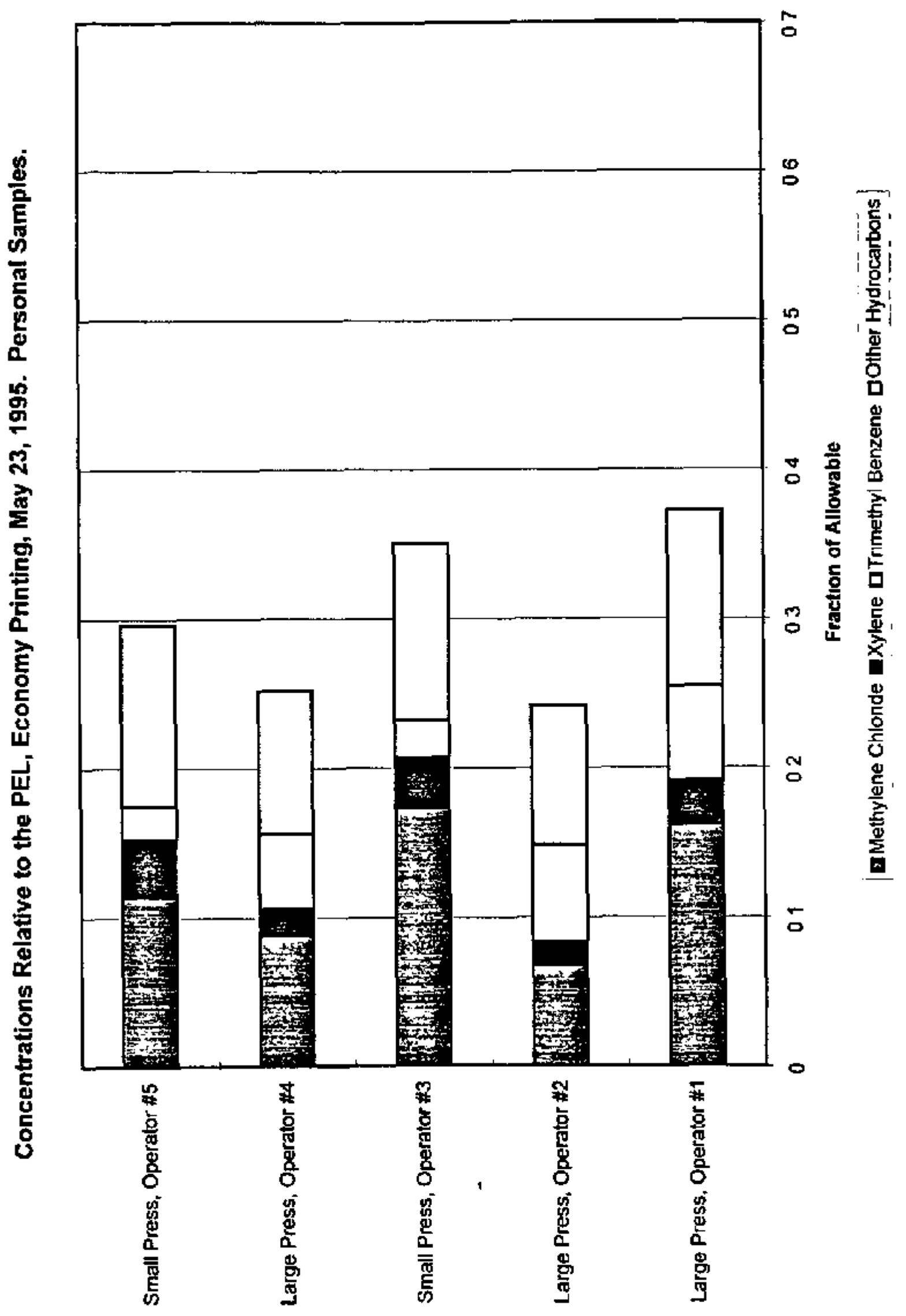




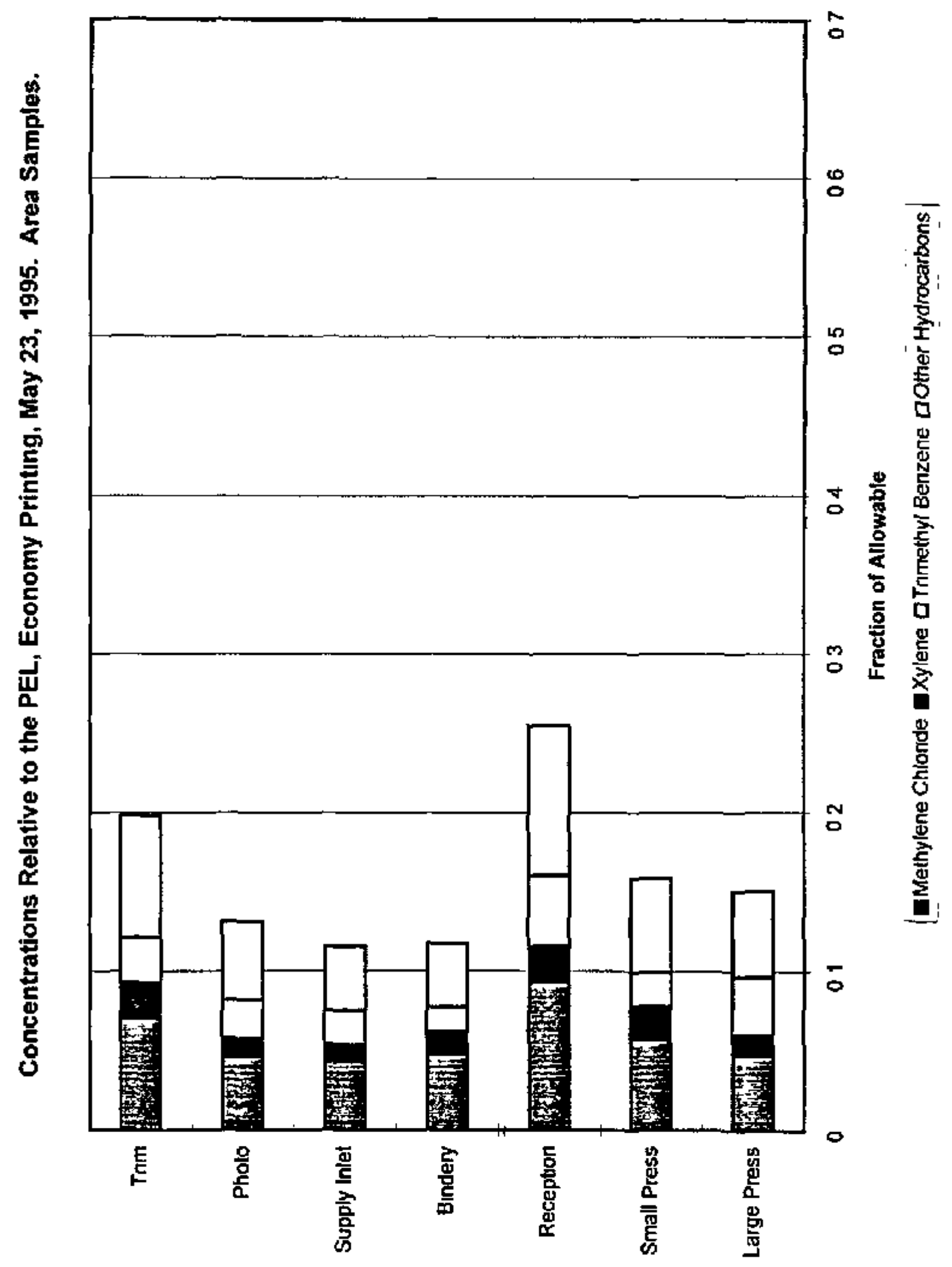




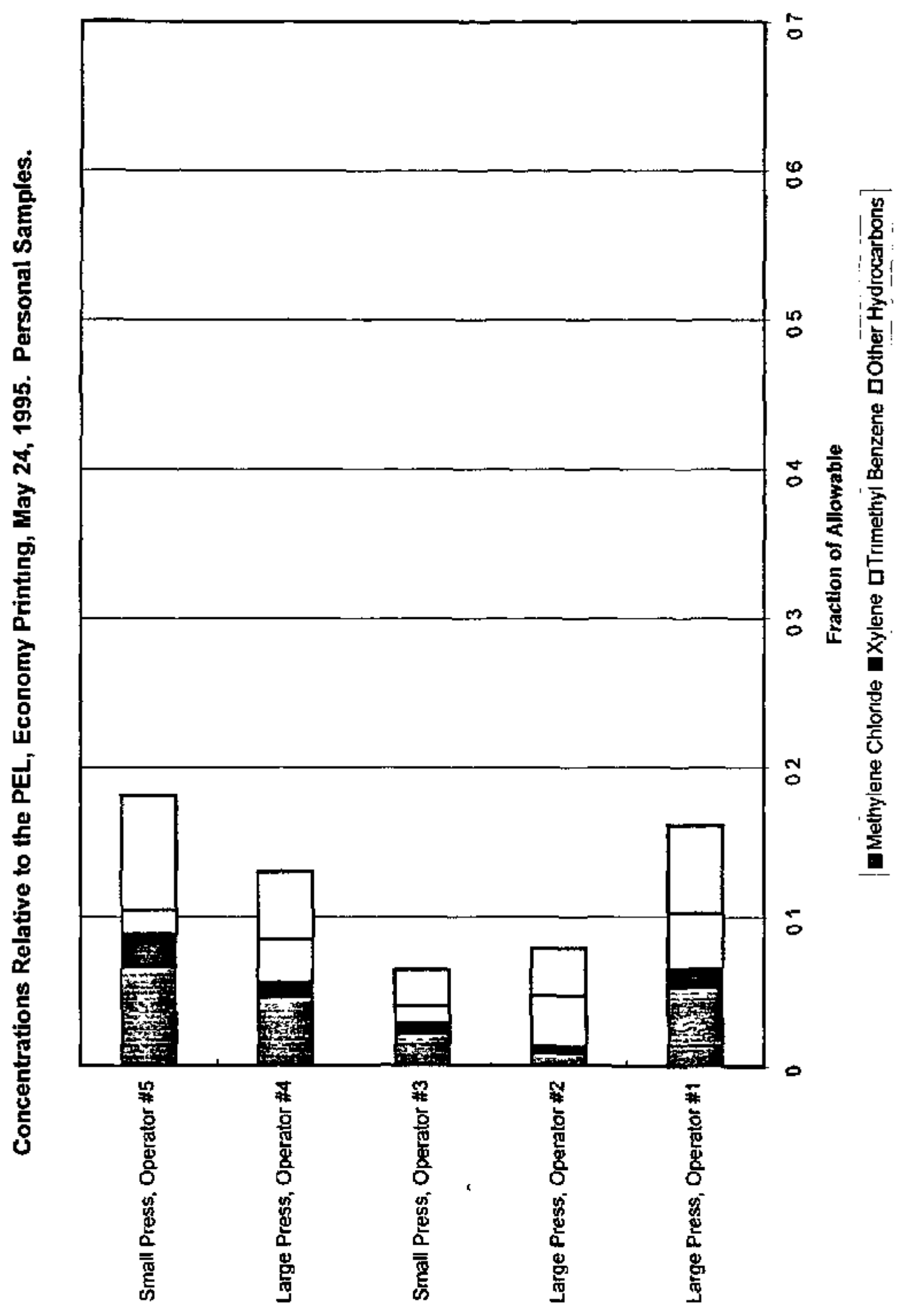




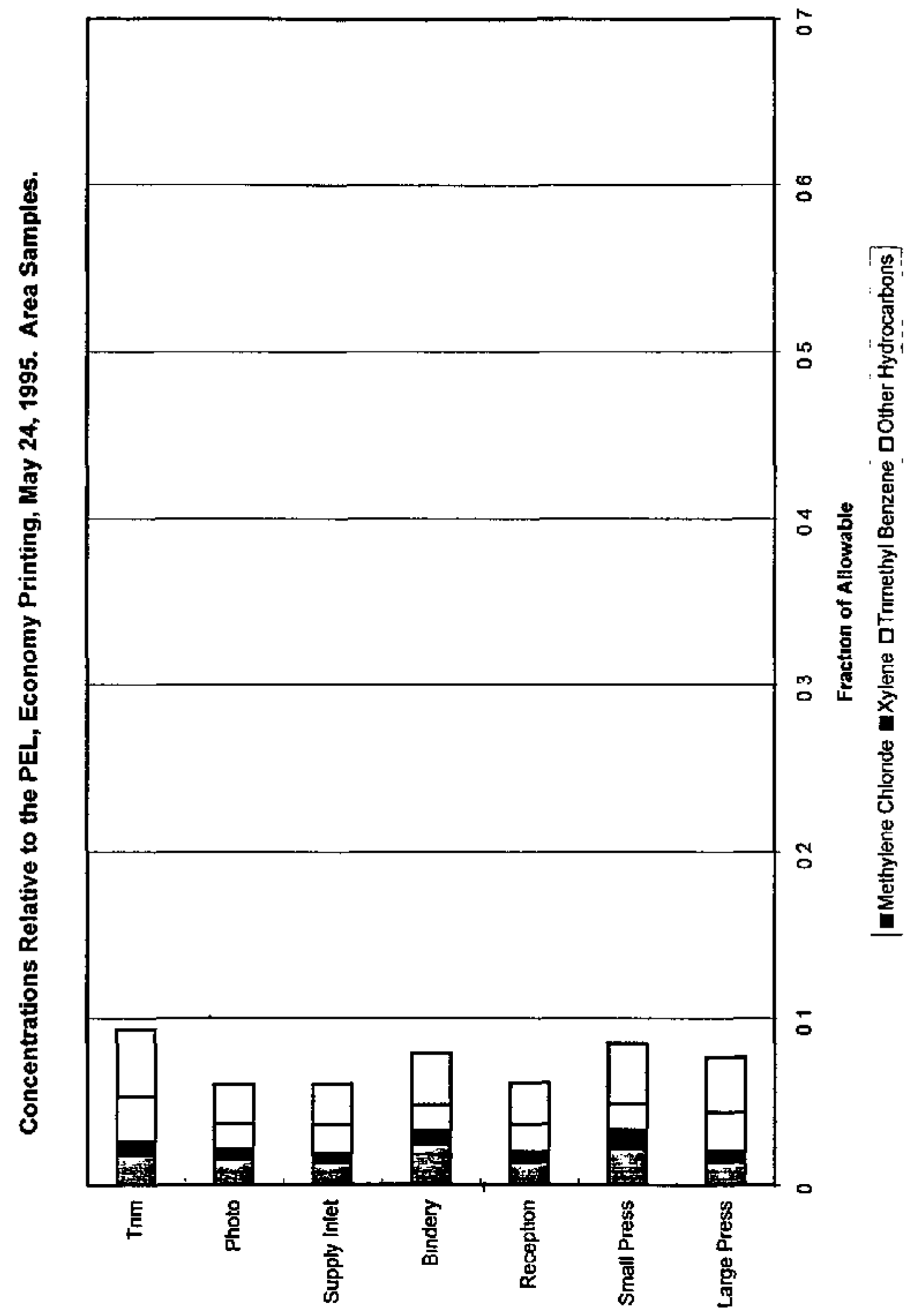




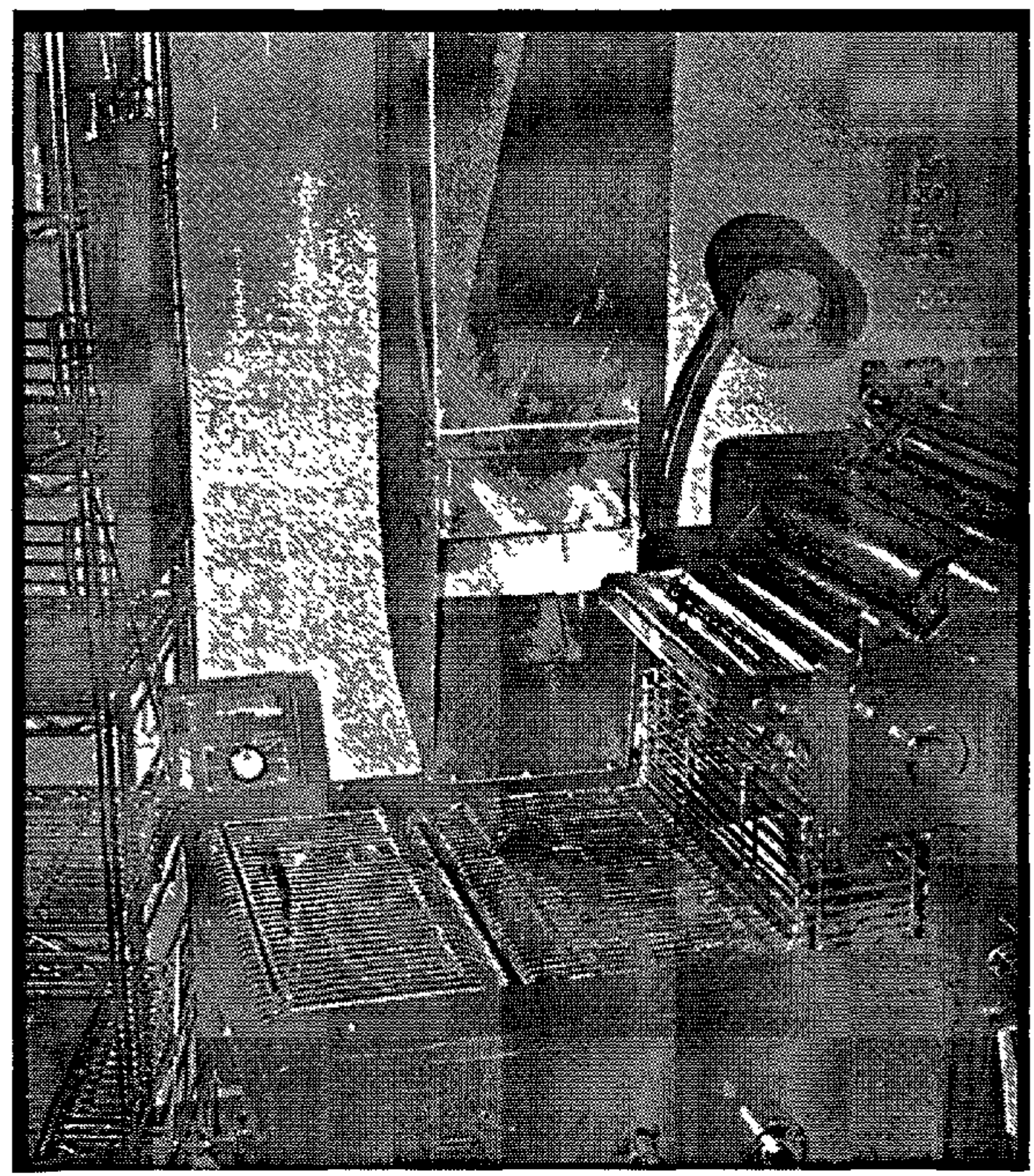

